\title{
City Leadership for Health and Well-being: Back to the Future
}

\author{
Agis Tsouros
}

\begin{abstract}
The new European Health Policy Framework and Strategy: Health 2020 of the World Health Organization, draws upon the experience and insights of five phases, spanning 25 years, of the WHO European Healthy Cities Network (WHO-EHCN). Applying the 2020 bealth lens to Healthy Cities, equity in health and human-centered sustainable development are core values and cities have a profound influence on the wider determinants of health in the European population. "Making it Happen" relies on four action elements applied and tested by municipalities and their formal and informal partners: political commitment, vision and strategy, institutional change, and networking. In turn, the renewed commitment by member states of the WHO Regional Committee to work with all spheres and tiers of government is a new dawn for city governance, encouraging cities to redouble their investment in health and health equity in all policies, even in a period of austerity. For phase VI, the WHO-EHCN is being positioned as a strategic vehicle for implementing Health 2020 at the local level. Healthy Cities' leadership is more relevant than ever.
\end{abstract}

KEYWORDS Health 2020, Healthy Cities, Urban governance, Urban health

\section{INTRODUCTION}

Strong local leadership was identified as an essential prerequisite for putting health high on the social and political agenda of cities from the very start of the WHO Healthy Cities Movement. Recognizing health as a core city value and creating the preconditions for each sector and every stakeholder to act upon their responsibility for health is a complex and lengthy process. First, it requires understanding then embracing a meaning of health beyond the absence of disease, encompassing physical, social, and mental well-being; second, it requires an appreciation of the nature and influence of the environmental, biological, social, and political determinants of health; and third, it involves constantly making the case that health is important to individuals, to society, and to socio-economic development. While the overall principles underlying such an approach may appear unchanged over the years, in reality, the meaning, the content, and the evidence underpinning these three requirements have vastly changed.

The increasing emphasis on enduring values such as the right to health, equity, sustainable development, and well-being, as well as the accumulating evidence on the social determinants of health have raised the stakes and the level of attention given to health. The other part of the equation is dealing with change, making things

Tsouros is with the World Health Organization Regional Office for Europe, UN City, Marmorvej 51, DK2100 Copenhagen, Denmark.

Correspondence: Agis Tsouros, World Health Organization Regional Office for Europe, UN City, Marmorvej 51, DK-2100 Copenhagen, Denmark. (E-mail: ats@euro.who.int) 
happen, making arrangements that enable decision makers, institutions, communities, and citizens work together for health and well-being. Again, terms such as intersectoral action for health and community empowerment have been central in the action vocabulary of Healthy Cities' policy development. The vocabulary has expanded and conceptually evolved both in scope and depth but the task at the core remains as challenging as ever-reaching out and engaging a wide range of agencies whose actions can impact on health. However, the world today is very different from the early phases of Healthy Cities in the late 1980s and 1990s. Several studies have drawn attention to challenges such as global interdependence and connectedness, the quickening pace of change, the added complexity of the policy environment, and the increase in uncertainty. New policy approaches and tools are needed to work effectively in such a world at all levels of government. ${ }^{1}$

\section{CITY LEADERSHIP FOR HEALTH}

City leadership, a golden thread running through 25 years and five phases of the WHO-EHCN, will be woven into phase VI (2014-2018). Municipalities have evolved as key drivers of city health development, providing not only leadership but continuity and adaptability in administrative structures and processes. Leadership for health and health equity is now more important than ever. It takes many forms and involves many actors, for example: international organizations setting standards and "goalposts", heads of governments giving priority to health and well-being, health ministers reaching out beyond their sector to ministers in other sectors, parliamentarians expressing an interest in health, business leaders seeking to reorient their business models to take health and well-being into account, civil society organizations drawing attention to shortcomings in disease prevention or in service delivery, academic institutions providing evidence on which health interventions work (and which do not) and research findings for innovation, and local authorities taking on the challenge of health in all policies. ${ }^{2}$

Such leadership for health in the twenty-first century requires new skills, often using influence, rather than direct control, to achieve results. Much of the authority of future health leaders will reside not only in their position in the health system but also in their ability to convince others that health and well-being are highly relevant in all sectors. Leadership will be not only individual but also institutional, collective, community-centered, and collaborative. Such forms of leadership are already in evidence. Groups of stakeholders are coming together to address key health challenges at the global, regional, national, and local levels, such as the global movement on HIV. Similar movements are emerging around noncommunicable diseases, environmental health, and health promotion.

Although cities are the focus of opportunity and prosperity, Zsuzsanna Jakab, the WHO Regional Director for Europe, acknowledges that they are also "the nexus of negative economic, environmental, and economic forces jeopardizing the lives and health of many inhabitants." ${ }^{3}$ Living and working in urban areas affects health and health prospects both positively and negatively, through a complex array of exposures and mechanisms. Although cities are engines of economic prosperity and often the location of the greatest wealth in a country, they can also concentrate poverty and ill health, ${ }^{4}$ often hidden. ${ }^{5}$ Roderick Lawrence's article in this special supplement $^{6}$ reviews this mix of assets and liabilities, highlighting both cities' attractiveness and prevalence of poverty. However, all these contributions also focus on the potential of city governments for promoting health. Lawrence dismisses the 
notion of cities as "passively depending on macro and microeconomic forces" in an increasingly global economy, and highlights a strengthened, active role for local governments.

Local governments are uniquely placed to provide leadership for health. Many social determinants of health operate at the local and community level. Municipalities have the capacity to influence the determinants of health and inequalities- "the causes of the causes" highlighted by Evelyne de Leeuw in this special supplement. ${ }^{7}$ They can promote the health and well-being of their citizens through their influence in several domains (identified by Malcolm Whitfield and associates also in this special supplement) such as health, social services, the environment, education, the economy, housing, security, transport, and sport. ${ }^{8}$ They can do this through various policies and interventions, including those addressing social exclusion and support, healthy and active living (such as cycle lanes and smoke-free public areas), safety and environmental issues for children and older people, working conditions, preparedness to deal with the consequences of climate change, exposure to hazards and nuisances, healthy urban planning and design' (neighborhood planning, removal of architectural barriers, accessibility and proximity of services), and participatory and inclusive processes for citizens. Inter-sectoral partnerships and community empowerment initiatives can be implemented more easily at the local level with the active support of local governments.

Local governments' democratic mandate conveys authority and sanctions their power to convene partnerships and encourage contributions from many sectors. Local governments have capacity to mobilize local resources and to deploy them to create more opportunities for poor and vulnerable population groups and to protect and promote the rights of all urban residents. Local leadership for health means understanding of the importance of health in social and economic development; and promoting accountability for health by statutory and non-statutory local actors, and ultimately acting as a guardian, facilitator, catalyst, advocate, and defender of the right to the highest level of health for all residents. ${ }^{10,}{ }^{11}$ Local leaders acting beyond their formal powers have the potential to make a difference to the health and wellbeing of local communities by harnessing the combined efforts of a multitude of actors.

Many of the public health challenges faced by the European Region today such as the noncommunicable diseases epidemic and unacceptable inequities, require wholeof-government and whole-of-society solutions. These, in turn, require stronger local leadership roles for health and, importantly, require large capacity to support and implement policies and interventions that draw on the contribution of many sectors and the active involvement of civic society.

\section{THE NEW EUROPEAN POLICY FOR HEALTH AND WELL-BEING-HEALTH 2020}

To respond to the public health challenges and the opportunities for health development, the WHO Regional Office for Europe developed a new policy framework and strategy for health and well-being-Health 2020 adopted at the highest political level by the 53 member states at the 62nd WHO Regional Committee for Europe in September 2012. ${ }^{12}$ Overall, Health 2020 puts increased emphasis and brings new evidence on the right to health, equity, well-being, and health in all policies through whole-of-government and whole-of-society approaches. These are framed by four pillars: the life course, focused action to address 
the major burdens of disease, strong people-centered health, care and public health systems, resilient communities, and supportive environments. The strategy makes the political, moral, and economic case for action and provides clear roles for local and community leadership and a platform for horizontal collaboration and vertical national local cooperation.

The imperative of city leadership for health is recognized as an essential strategic dimension of Health 2020. It will provide a unifying and coherent action framework to accelerate the attainment of better and more equitable health and well-being for all, adaptable to the realties that make up the European Region. Health 2020 builds on the legacy and experience of the Region with the values and principles of Health for All, the Ottawa Charter for Health Promotion, the Tallinn Charter: Health Systems for Health and Wealth, Health 21, and declarations adopted at ministerial conferences on environment and health. Health 2020 recognizes the key importance of action at the local level and the central role local governments can have in promoting health and well-being. Health 2020 signals a new dawn for health and well-being in Europe with a new value-based approach for shared governance for health, acknowledging municipalities as key agents of change.

Health 2020 has a reciprocal, symbiotic relationship with Healthy Cities. It is acknowledged that the experience and ideas of Healthy Cities have contributed significantly to shaping this new Health Policy framework and strategy. In turn, Health 2020 underpins and reinforces the values and strategic goals of Healthy Cities. It deepens and expands its evidence base and provides a framework for connecting with stakeholders at all levels of government. Cities' accumulated wealth of evidence and experience highlights both challenges to urban health and the key role of local governments in securing health and well-being into the twenty-first century.

Health 2020 provides a timely and strong unifying framework for phase VI of the WHO European Healthy Cities Network. It builds on and reinforces the fundamental values, principles, and work that have been at the core of Healthy Cities since its inception. Cities are uniquely placed to provide leadership for health and well-being. In the complex world of multiple tiers of government, numerous sectors, and both public and private stakeholders, local governments have the capacity to influence the determinants of health and inequities

\section{CITY GOVERNANCE: UNLOCKING THE POTENTIAL}

At the Regional Committee in September 2012, member states committed to the "whole-of government-approach" of Health 2020, acknowledging in the words of a key study, which informed Health 2020, on Governance for Health, "13 "that regional and local sectors therefore have increasing relevance, making effective multi-level governance as important as cross-sectional and participatory governance". It has already been indicated how the Health 2020 strategy incorporates values, approaches, strategic objectives, and priorities which have evolved over the five phases of the WHO European Healthy Cities Network, and the important role of city governments in addressing the wider determinants of health. ${ }^{14}$ Yet unlocking this potential, "Making it happen," turning aspiration into reality on the ground, on city streets, and in the homes of city residents, is necessarily built on a framework of four basic elements developed by Healthy Cities. At a practical level, good urban governance requires political commitment, vision, strategic thinking, institutional change, and forums and networks to support innovation, exchange of ideas, and 
learning. These elements for action are summarized in the requirements for phase $\mathrm{V}^{15}$ of the WHO-EHCN and in Urban Health, Global Perspectives. ${ }^{16}$

\section{Political commitment}

The first element for action success is political commitment. In Health 2020, leadership is an important element of "Making it Happen." Of the many actors at all levels of government, city mayors can make a unique major contribution. But health leadership requires the mobilization and support of many players. Health should not be regarded as one party political issue. Ensuring the engagement and commitment across the political spectrum and the support of important stakeholders is a critical precondition for sustainable change. Healthy Cities are political but not partisan. Consensus is a critical success factor. Sustained commitment over the many phases of Healthy Cities has not depended upon electoral fortune.

Political decision makers cannot turn their institutions and policies upside down every time an international declaration calls for change. Healthy Cities have provided a compass, promoting health as a core value in city policies and development plans and serving as a beacon of social justice and participatory governance. Cities in the forefront of development must possess the leadership, resilience, skills, and expertise to respond to new ways of thinking and acting to cope with harsh realities and new opportunities. Courage and vision are required of city mayors, whose remit does not often extend to formal responsibility for health or health services. Health is the business of every sector and mayors have a key role in orchestrating the contribution of many actors. Their power and influence can persuade diverse organizations that health is an asset in citizens and workforce, itself prerequisite for achieving their different agendas.

The trend towards devolution in European states in the two decades before the second millennium has enhanced municipalities as powerful agents of change. Most Nordic countries and notably Finland have transferred the main responsibility for health promotion to the municipal level. Public health in England was transferred to municipalities from the National Health Service in 2013. The experience of Healthy Cities is that local governments can have a unique leadership position and convening power to protect and promote the health and well-being of their citizens. From the beginning, membership of the $\mathrm{WHO}-\mathrm{EHCH}$ was conditional upon city mayors signing a formal commitment to the values, principles, and goals of Healthy Cities and to funding an infrastructure for developing health plans and programs.

\section{Vision and strategy}

The second prerequisite for sustainable action is a city vision with a strong health dimension. Many city governments now have powers and responsibilities to define a future characterized by a prosperous local economy, sustainable development, and a cohesive city life. The 11 qualities of a healthy city (Table 1) were summarized in the very first WHO Healthy Cities Paper ${ }^{17}$ produced at the beginning of phase I (19881992) and highlighted as a "vision of what the city can become" in the Twenty Steps guidance $^{18}$ published at the end of this phase. Guidance has been renewed over many years, for example, adapting to Agenda 21 on sustainable development and to new evidence on the social determinants of health.

Although an aspirational document is essential, in itself it is insufficient for engineering change. Integrated strategic planning is required to maximize synergies, and health and equity are required in all local policies to guide concrete actions. City Health Plans were developed in phase II (1993-1997), City Health Development Plans were centerpiece of phase III (1998-2002) ${ }^{19}$, and broadened in phase IV (2003-2008). ${ }^{20}$ As the mayor of Sandnes declared, "City health development plans 
TABLE 1 Eleven qualities of a healthy city

1. A clean safe high-quality environment including affordable housing

2. A stable ecosystem

3. A strong, mutually supportive, and non-exploitative community

4. Much public participation in and control over decisions affecting life, health, and well-being

5. The provision of basic needs (food, water, shelter, income, safety, and work) for all people

6 . Access to a wide range of experiences and resources with the possibility of multiple contacts, interaction, and communication

7. A diverse, vital, and innovative economy

8. Encouragement of connections with the past, with the varied cultural and biological heritage, and with other groups and individuals

9. A city form (design) that is compatible with and enhances the preceding characteristics

10. An optimum level of appropriate public health and care services accessible to all

11. A high health status (both a high positive health status and low disease status)

tell you where you want to be and how to get there." Health 2020 puts special emphasis on national and sub-national (regional and local) policies, strategies, and plans. The challenge is twofold: to ensure that health becomes a core value in the city's vision for future development and also to develop a comprehensive city health strategy or plan that addresses the determinants of health and which draws on the contribution of several sectors.

3. Institutional change-supporting innovation

A third prerequisite for local action is institutional change. In the process of preparing for action, many cities discover that their organizational structures and management processes do not serve their present needs and that they lack the necessary capacity for change and innovation. A robust project organization has certainly proved critical in determining the impact and sustainability of European Healthy Cities. From the outset in 1987 through to phase V (2009-2013) cities applying for membership of the WHO-EHCN are required to "secure political support and adequate resources" and put in place "structures to facilitate the implementation of goals related to a healthy city. ${ }^{21}$ " According to city representatives, a key success factor "is a strategically located office and a well-organized team with good management and communication skills. ${ }^{22 "}$ Most healthy cities have both formal political structures and informal working relationships with statutory, voluntary, private, and public agencies. An enduring commitment of Healthy cities to community participation and empowerment is now a core principle of Health 2020. In this Special Supplement Mark Dooris and Zoe Heritage highlight a variety of mechanisms to inform and engage city populations. ${ }^{23}$ In a period of austerity and constraints on public finances, it is vitally important to strengthen and utilize the assets of individual and community resilience.

Action to improve population health requires the cooperation of decision makers in sectors responsible for shaping wider determinants. Traditional departmental silos operating in many local governments are inappropriate because health is everyone's business. In the section on "Making it Happen," Health 2020 highlights "Adding value through partnerships and partners for health." In all phases, cities applying for membership of the WHO-EHCN are required to establish an inter-sectoral committee for health. Twenty Steps has provided practical guidance and this structure has remained a key feature of all phases. Technical cooperation is 
necessary to undertake collaborative projects and produce a strategic city health development plan. Key sectors are illustrated as pillars of a Parthenon on the front cover of WHO guidance on producing city health plans $^{24}$ and include, besides health and social services, business, industry, transport, education, economic, and environment sectors. In practice, partnerships within the health and social services sectors dominated earlier phases of the WHO-ECHN and still account for most collaborative partnerships. ${ }^{25}$ However, in this Special Supplement, Alistair Lipp, Tim Winters, and Evelyne De Leeuw reveal that in phase IV more cities engaged with other sectors: $64 \%$ at the highest level with the education sector, $28 \%$ with the transport sector, and $42 \%$ with urban planning, reflecting a core theme of this phase. Cities have generally moved beyond the planning stage to implement collaborative projects and programs. ${ }^{26}$

4. Networking

Networking is a fourth prerequisite. Our WHO- EHCN is one of the strongest networks around the world and there are now 23 active National Networks covering over 1,500 cities in the European Region. ${ }^{27}$ They bring together and enable collective learning. Through sharing experiences, networks support innovation while helping cities avoid risk and repeating the mistakes of others. They increase the efficiency of cities and provide the basis for capacity building, change, and innovation. Informal networks often complement formal partnerships, and can operate both within and beyond particular cities. Within a city, informal networks might shadow formal committee structures, sourcing and disseminating new ideas and practical solutions to new challenges and perennial problems. They provide support and encouragement, and help sustain key professionals and community representatives through adversity. Health 2020 identifies the power of electronic communication, encouraging cities to embrace social networking as an important aspect of "Smart Governance." "Approaches need to be adaptive and mirror the complexities of causality, because complex and wicked problems have no simple linear causality or solution. Decentralized decision making and self-organizing or social networking help stakeholders respond quickly to unanticipated events in innovative ways. Interventions should be iterative and integrate continuous learning. .... Anticipatory governance with participatory foresight mechanisms can also support societal resilience by shifting policy from risks to addressing more fundamental systemic challenges and jointly deliberating the social and value-and science-based dimensions of public policy."

Healthy cities have a huge experience in working together within an inspiring and supporting framework. Inter-sectoral partnerships were pioneered when the primary focus of European municipalities was the departmental provision of services; social care, urban planning, environmental health, education, waste management. Twentyfive years of realpolitik has refocused municipalities on city development and taken many departments out of their silos and into effective inter-sectoral partnerships.

Though these partnerships often embrace central, regional, and provincial governments, their primary modus operandi is horizontal: working together across departments, sub-contractors, independent agencies, and the local voluntary and community sector. Health 2020 and the companion report Governance for Health offer an opportunity to re-forge vertical partnerships. It concludes that success requires a common purpose and broad collective efforts by people and organizations across society and in every country. It is an opportunity for cities to engage more fully with different spheres and tiers of government within member states of the WHO region, with the European Union and international organizations active 
within the European Region. For Healthy Cities and national governments alike, there is the prospect of a new model of cooperation. Health 2020 sets out a common purpose and a shared responsibility.

\section{CONCLUSION}

The economic crisis has transformed the socio-economic landscape from expanding budgets over decades of relative prosperity to highly constrained public finances now shaping policies across the whole Region, at all levels of government. The weakest will continue to pay the highest price. Desperation infects a generation of unemployed young people. A growing intolerance towards migration and diversity compromises social solidarity. The crisis is driving enormous adjustments in macroeconomic policies which can compromise the core value of equity in health.

Breaking through these dark clouds of austerity, Health 2020 presents a new dawn for health and well-being in Europe. The strategy reaffirms the intrinsic value of health to humanity enshrined in the founding constitution of WHO in 1948. But equally, it highlights health as a resource, as human capital for economic growth and sustainable development. Investing in health is an essential precondition of economic prosperity. Age-friendly city policies and plans for healthy aging will defy those who claim that growing numbers of older people are a burden on health and social care services.

The phase VI (2014-2018) of the WHO-EHCN framework is shaped around the goals and objectives of the new European policy and strategy for health and wellbeing-Health 2020. Health 2020 reinforces the values and principles on which Healthy Cities is based, provides a supportive and encouraging environment for the next phase and offers the potential to strengthen the policy salience and to broaden both the strategic and operational scope of the work of Healthy Cities. Most importantly, Health 2020 recognizes the important role of local governments in developing health and is especially focused on whole-of-government and whole-of-society approaches to health. The 8th Global Conference on Health Promotion in Finland early in 2013 reiterated the importance of health in all policies in addressing the consequences of public policies on health determinants. The aim is to improve the accountability of policy-makers for health impacts at all levels of policy making and strengthen the governance for health. The strategy must be embraced and implemented by all levels of government working together and cities are well placed to make an effective contribution. Many of the pioneering Healthy Cities-including Milan, Liverpool, Liege, and Rotterdam-were experiencing deindustrialization and high levels of unemployment and an earlier era of economic crisis. Their resilience and vision in the face of adversity can be repeated in the next phase of Healthy Cities.

\section{ACKNOWLEDGMENTS}

This Special Supplement is supported by the World Health Organization Regional Office for Europe.

\section{REFERENCES}

1. Swanson D, et al. Seven guidelines for policy making in its uncertain world. In: Swanson D, Bhadwal S, eds. Creating Adaptive Policies: A Guide for Policy Making in an Uncertain World. London: Sage; 2009. 
2. United Nations, Department of Economic and Social Affairs, Population Division. World Urbanization Prospects, the 2009 revision: Highlights. New York: United Nations; 2010.

3. Jakab Z. Contextualizing health: accounting for the urban environment. Harvard Int Rev. 2012; 34(1): 46-51.

4. United Nations, Department of Economic and Social Affairs, Population Division. World Urbanization Prospects, the 2009 revision: Highlights. New York: United Nations; 2010.

5. World Health Organization/UN HABITAT. Hidden Cities: Unmasking and overcoming Health Inequities in Urban Settings. Kobe: WHO; 2010.

6. Lawrence RJ. Urban health challenges in Europe. J Urban Health. 2012. doi:10.1007/ s11524-012-9761-z.

7. De Leeuw E. Evaluating WHO Healthy Cities in Europe: issues and perspectives. Journal of Urban Health. 2012. doi:10.1007/s11524-012-9767-6.

8. Whitfield M, Machaczek K, Green G. Developing a model to estimate the potential impact of municipal investment on city health. J Urban Health. 2012. doi:10.1007/s11524-012-9763-x.

9. Barton H, Grant M, Mitcham C, Tsouros C. Healthy urban planning in European cities. Heal Promot Int. 2009; 24: i91-i99.

10. Tsouros A. City leadership for health and sustainable development. Heal Promot Int. 2009; 24: i4-i10.

11. Environmental health inequalities in Europe. Assessment report. Copenhagen, WHO Regional Office for Europe, 2012 (http://www.euro.who.int/_data/assets/pdf_file/0010/ 157969/e96194.pdf). Accessed $8^{\text {th }}$ August 2013.

12. World Health Organization Regional Office for Europe. Health2020: Policy Framework and Strategy. EUR/RC62/8. Copenhagen: WHO; 2012.

13. Kickbusch I, Gleicher D. Governance for health in the 21st century. Copenhagen: WHO Regional Office for Europe; 2012.

14. Grady M, Goldblatt P, eds. Addressing the Social Determinants of Health: the Urban Dimension and the Role of Local Government. Copenhagen: World Health Organization Regional Office for Europe; 2012.

15. Phase V (2009-2013) of the WHO European Healthy Cities network: goals and requirements. Copenhagen, WHO Regional Office for Europe, 2009 (http://www.euro.who.int/_data/ assets/pdf_file/0009/100989/E92260.pdf). Accessed $8^{\text {th }}$ August 2013.

16. Tsouros A, Green G. Healthy Cities: lessons learned. In: Vlahov D, Ivey Boufford J, Pearson C, Norris L, eds. Urban health: global perspectives. San Francisco: Josset-Bass; 2010.

17. Hancock T, Duhl T. Promoting health in an urban context. WHO Healthy Cities Papers No.1. Copenhagen: WHO Regional Office for Europe; 1988.

18. WHO Regional Office for Europe. Twenty Steps for Developing a Healthy City. Copenhagen: WHO; 1992.

19. Green G, Acres J, Price C, Tsouros A. City health development planning. Heal Promot Int. 2009; 24(Supplement 1): i72-i80.

20. Green G. Intersectoral planning for city health development healthy. J Urban Health. 2012; 89(2): 247-257.

21. WHO Regional Office for Europe. Phase V (2009-2013) of the WHO European Healthy Cities Network; goals and requirements. Copenhagen, Denmark: WHO Regional Office for Europe; 2009. http://www.euro.who.int/_data/assets/pdf_file/0009/100989/ E92260.pdf. Accessed on November 14, 2012.

22. Lipp A, Winters T, De Leeuw E. Evaluation of partnership working in phase IV of the WHO Healthy Cities network. J Urban Health. 2012; doi:10.1007/s11524-0119647-5.

23. Dooris $M \&$ Heritage Z. Healthy Cities: facilitating the active participation and empowerment of local people. J Urban Health. 2011; doi:10.1007/s11524-011-96230 .

24. WHO Regional Office for Europe. City Health Planning: the framework. Copenhagen, Denmark: WHO Regional Office for Europe; 1996. (Document EUR/ICP?HCIT 94 01/ MT06/7). 
25. Green G, Price C, Lipp A, Priestly R. Partnership structures in the WHO European Healthy Cities project. Heal Promot Int. 2009; 24(Supplement 1): i37-i44.

26. Lipp A, Winters T, De Leeuw E. Evaluation of partnership working in phase IV of the WHO Healthy Cities network. J Urban Health. 2012; doi:10.1007/s11524-011-9647-5.

27. Heritage Z \& Green G. European National Healthy Cities Networks: the impact of an elite epistemic community. J Urban Health. 2012; doi:10.1007/s11524-012-9777-4. 